interested parents and the dental profession. As a result of information gained from this study, several projects already have been initiated or are planned.

\title{
Acknowledgement
}

Sincere appreciation now is expressed to the many volunteer workers and other persons, without whose cooperation and assistance the various aspects of this study would not have been possible. Special thanks are due Dr. Mamie Jo Jones, and her staff, of the Georgia Department of Education, Services for Exceptional Children, and to Mrs. Louise Stewart, Executive Secretary, Georgia Association for Retarded Children, and her staff.

\section{SOME CHANGES REQUIRED TO INCREASE THE PUBLIC'S UTILIZATION OF PREVENTIVE DENTISTRY*}

\author{
By S. Stephen Kegeles, Ph.D. ${ }^{* *}$
}

If you want to get your inherited beliefs questioned, you are dared to read this paper.

At the beginning of this discussion, it seems appropriate to ask not only why people seek or fail to seek dental care, but also to ask what need be done to increase the number of persons who visit dentists for preventive purposes. This paper will use "preventive" in terms of visits to dentists to prevent the occurrence of more serious dental problems than now exist, that is, visits to dentists for annual or semi-annual checks as differentiated from symptomatic visits only. Such a concept of "preventive" leads to a discussion of three topics: (1) the knowledge about who and why people visit or fail to visit dentists for preventive care; (2) the role of the private dental practitioner, to date, in conditioning people to make dental visits on a preventive basis, and (3) the procedure needed to persuade people to do so who do not now visit dentists preventively.

Who Makes Preventive Visits and Why?

The extent of the problem to be faced demands initial priority. (1) In an analysis of all of the available data-some seven studies-it was concluded about six years ago that about 35 percent of the population visits dentists at least once during any year. ${ }^{1}$ There is no apparent reason to think that the percentage of the population making such visits has increased greatly during the last six years. (2) About 15 to 20 percent of the population visits dentists on a regular periodic basis for the purpose of examination or prophylaxis in the absence of symptoms during any one-year period. ${ }^{1}$ About 45 percent of the population claims to visit

* Presented March 11, 1967, in the Conference on Dental Care and Dental Health Education at Columbus, Ohio, and sponsored by the Ohio State Dental Association in Cooperation with the State Department of Health.

* Associate Professor of Public Health Administration, School of Public Health, The University of Michigan, Ann Arbor, Michigan 48104. 
dentists for preventively oriented purposes during the "most recent" three-year period:-an amount of time which exceeds the recommended practice greatly.

On the basis of this information, an explanation is available to explain why less than half of the population visits dentists on a regular, periodic, symptomfree basis and why much more than half of the population fails to follow practices which are likely to avoid serious dental problems. Most of the data from research to be cited were gathered on people who had available to them, and to their families, dental care at no direct cost. The population included those who work in companies in which dental service is provided as part of the policy of a company or its union, and also those who are provided dental care, at no direct cost to themselves, on the basis of eligibility in health clinics. These data indicate that (1) persons likely to seek dental care on a regular, periodic basis, according to almost every study reported, have greater amounts of education, higher incomes, and work in jobs which have higher status, whereas persons with less education, lower incomes, working in jobs of lower status seem much less likely to seek dental care on a regular basis even when such care is available at no cost to them,3. . : (2) people who visit dentists for symptom-free examinations generally behave in preventive ways in regard to other health matters (for instance, a national sample, studied in 1,500 households and completed about two years ago, showed that people who visited dentists for check-ups also visited physicians for check-ups more frequently, and reported voluntarily for periodic $x$-ray screening more frequently than did their counterparts who failed to make preventive visits to dentists ${ }^{2}$ ); and (3) when the extent of teeth salvaged is defined as the number of teeth filled divided by the number of teeth attacked by caries, as a rough measure of the frequency of visiting dentists for preventive reasons, there appears to be a general orientation of the family to dental care. A fairly close relationship exists between the extent to which each parent's teeth have been saved, while a high correlation is found between the repair of children's teeth and their mothers' teeth among white populations."

\section{Why People Seek Preventive Care}

The reasons why people seek preventive care can be divided readily into those which lead people to seek care (the motives) and those which people need to overcome to get care (the barriers).

It has been found that a person is not likely to take action for his health unless (1) he thinks himself susceptible to the disease in question, (2) concludes that the disease in question would have serious effects upon his life if he should contract it: (3) is aware of certain actions that can be taken and thinks that these actions may reduce his likelihood of contracting the disease, or may reduce the severity of the disease should he contract it; and (4) decides that the threat to him of taking the action (the barrier in the situation) is not as great as the threat from the disease itself. ${ }^{i}$

In one study, it was found that "respondents who believe themselves highly susceptible to dental problems made more preventive visits than those who believed themselves barely susceptible; that those respondents who believed that dental problems would be serious when they occurred made more dental visits than those who did not hold this belief; more respondents, who believed that they could take generally beneficial actions against dental problems, made more preventive dental visits than those who did not hold this belief." Almost 80 percent of those who held all three of these beliefs, moreover, made preventive dental visits, while none of the respondents categorized as low on these three variables made preventive visits. ${ }^{3}$ 
Persons who failed to express great fear about the pain of dentistry and who were least anxious about the whole process of dentistry seemed more likely to make visits to dental offices for regular periodic care than their counterparts. ${ }^{3}$

In a second study of the same population-a population, be reminded, that did not have to pay directly for its own dental services-it was found that the major motivating factors were a belief that serious dental problems were likely to happen to them, and that visits to dentists on a regular, periodic basis would keep such serious problems from occurring. The same barriers-fear of pain and anxiety about treatment--differentiated the two groups. ${ }^{4}$

For a general population, the possession of two beliefs appeared to differentiate those people who visited dentists preventively from those who failed to do so. These beliefs were that it is possible to do something to prevent diseased gums or decay of teeth from becoming very serious, and the belief that visits to dentists on a regular, periodic basis, coupled with toothbrushing on a regular basis would be efficacious in prevention. ${ }^{\circ}$ Finally, an additional belief seems to be of extreme importance. This belief is that dental decay occurs as a natural process, as differentiated from the belief that one is born with bad or soft teeth or that one has an hereditary disposition for bad teeth. ${ }^{3,4}$ It now is time to stop and summarize the information presented so far: (1) Approximately 40 percent of the population visits dentists each year; (2) between 20 and 40 percent of the population seems to make visits to dentists on a regular, periodic basis over a threeyear interval; (3) persons who make periodic preventive visits seem more likely, than those who fail to make such visits, to think that (a) they are likely to get dental disease, (b) such dental disease will be serious for them (though this finding seems true for some studies only and not for others), (c) there is something that can be done to prevent dental disease from becoming worse and such activities are truly effective, and finally, (d) the benefits accrued from visiting dentists are more important than the problems encountered in an attempt to do so.

These data indicate rather well, then, what people need to know and accept in order for them to visit dentists on a preventive basis. They need to know that dental problems will affect them seriously if they fail to take preventive and early remedial action, and they need to understand that such preventive and early remedial action, will avoid serious problems and can be provided by dentists.

\section{The Contributions of Dentists to Preventive Dental Behavior}

Information about preventive dental behavior would seem easy for a dentist to impart; in fact, one might suggest that the profession has been imparting this information for years. The data cited, however, make it obvious that much of the population has either not heard or not believed the profession. Just how much has the profession contributed, by its own actions, to this failure of the population to attend to professional words? Two, out of many possible, activities may be selected in which the profession's behavior could have convinced people that dentists really cared whether the teeth of the public received care or not. These activities are (1) fluoridation of drinking water and (2) the provision of dental care for elderly and chronically ill patients at home.

Fluoridation. It has been stated frequently that the most important dental preventive in existence is the fluoridation of a community's drinking water. If the dental profession had been thoroughly interested in the prevention of dental problems, one might expect that its organized groups should have been vigorously participating in, and more interested about fluoridation than any other dental activity. To some extent this expectation has been born out. The Division of Den- 
tal Health of the Public Health Service has one unit devoted entirely to fluoridation. The American Dental Association has devoted two separate issues of its entire journal to fluoridation and has promoted fluoridation nationally at every possible opportunity. The private practitioner of denistry has read about this activity. The most recent data-albeit, quite old data-indicate that about two percent of a national random sample of private dentists claim to have participated actively in any way to gain fluoridation in their communities." That number may have increased; but the increase probably has not been great.

Even more important has been the effect of this failure to participate in gaining fluoridation. In a national study of 1,038 cities, in which decisions about fuoridation were made on a nonreferendum basis, a number of questions were asked of health officers and publishers of newspapers about the extent of support for fluoridation which came from the various community organizations. ${ }^{10}$ In communities where dental societies failed "actively to support fluoridation," 26 percent of the communities adopted fluoridation. Conversely, 42 percent of those communities, in which the dental societies actively supported fluoridation, accepted fluoridation by administrative decision. Evidence was provided, hence, that a 2:1 ratio for successful adoption developed in those communities where the dental societies provided support. An additional way for dentists to push fluoridation is to influence one's health colleagues, such as members of the medical society and the health officer. It was found, in the study quoted, that but 19 percent of the communities in which the medical society failed to support fluoridation adopted it by administrative edict. The percentage doubled to 38 percent when the medical society gave token support only, and to 46 percent where the medical society provided "active support to fluoridation." Seventeen percent of the communities accepted fluoridation when the health officer was passive, and 44 percent of the communities accepted fluoridation when the health officer assumed an active role. ${ }^{10}$

Dental Care for the Chronically Ill, Homebound and Nursing-Home Patients. The second area selected for testing the contribution of dentists to preventive behavior was that of the provision of dental care for the chronically ill, homebound patient and the patient in a nursing home. About eight years ago the Division of Dental Public Health of the Public Health Service started a demonstration program in Kansas City that was organized to determine the dental needs of the homebound, chronically ill persons and elderly persons in nursing homes. Two of the less obvious objectives of the program were (1) to stimulate organized dentistry to provide dental care for patients country-wide who were chronically ill and residents of nursing homes, and (2) to get greater Kansas City to take over the program after the Public Health Service completed its demonstration.

A document, released in $1961,{ }^{11}$ reported the success of the program. In many ways, the program was designated as quite successful; a large number of residents of nursing homes were provided dental care for the first time in many vears as were a number of homebound, chronically ill persons. Assessments were made of the dental needs of the study-population and of the number and type of dental man-hours which were necessary to treat these needs. A program for teaching dental students how to cope with the elderly and the ill at home was started at the School of Dentistry in Kansas City. Since that time, a number of other dental schools-the latest number reported was nine-have organized similar programs. A number of manufacturers designed lightweight portable dental equipment, long-handled toothbrushes for arthritic patients, and a multiplicity of gadgets. 
When the demonstration program ended, in 1961, Kansas City regressed to its position prior to the program. To the best of knowledge, not even a vestige of the demonstration remains in Kansas City. A survey was begun to determine the interest and willingness of private dental practitioners in Kansas City, and in a portion of Kansas and Missouri, to treat patients of nursing homes and chronically ill, homebound patients. A report never was written, inasmuch as a presurvey indicated neither interest not willingness of dentists in practice to treat such patients, to use portable equipment, or to provide treatment outside of their offices.

\section{What is Needed to Convince People to Visit Dentists Preventively?}

A question, assuming that dentists want to increase the number of people who take care of their teeth on a preventive rather than a survival basis, now may be asked, "Where can dentists exert their greatest impact?" It would be simple to list data, if they were available, on the relative values of working with groups, as compared with interpersonal technics, and the potential effectiveness of mass communication in persuasion. A social psychologist will not find the task that simple. He may agree that there are apt to be useful effects from education in dental health both in the office and in the school. He will have to agree, however, that the greatest effect on patients will come only after changes, already started, occur to a much greater extent within the dental profession itself. Specifically, a need will exist to experience (1) an increased emphasis in changing both the entrance requirements for students and the curricula of schools of dentistry, and (2) increased changes in the practice of dentistry, before one should expect much change in the population.

Changes Necessary in Entrance Requirements and Curriculum. It seems evident on a probability basis, that students who care most about what happens to people are those who major in the social sciences, and, on a probability basis, that those who are least concerned about people major in the physical and biological sciences. Yet students with intensive background in the biological and physical science-those who have majored in premedical or predental studies-have been admitted most readily to dental schools in the past.

What, then, have these previous students wanted from dentistry? Studies of high school students, who see dentistry as a potential career, ${ }^{12}$ and of dental students, ${ }^{13}$ indicated a few years ago that the major drawing power of dentistry was (1) a desire to be a professional man, (2) a desire to be one's own boss, (3) a desire to experience a better than average income, (4) a desire to work with one's hands, and finally, toward the bottom of the list, ${ }^{5}$ a desire to help people. ${ }^{13}$

A number of students who seem to have a genuine desire to help people do enter schools of dentistry. Studies completed in Ohio's dental schools seem to show that this group includes a substantial number of first-year students. ${ }^{14} \mathrm{Un}$ fortunately, from the traditional curriculum, fewer senior dental students than freshman dental students, by far, wished to help people.

What is there about the curricula of professional schools which has led to a decreasing concern about people? Courses which teach the clinical practice of dentistry were found to be in greatest esteem both by the faculty and the student. ${ }^{14}$ The courses in basic sciences were defined as obstacles which one had to overcome before one really could become immersed in important things. ${ }^{1+}$ Given this orientation, it did not seem likely that concern about the population to be served would have much impact within the curriculum of a school.

It should be emphasized that these conclusions about the dental student and his curriculum have been stated in the past tense purposely. All of the studies 
were reported five and six years ago. More importantly, these studies all were supported from funds obtained by and through the Survey of Dentistry and the American Association of Dental Schools. As a result of this searching self-analysis-a most difficult process-schools of dentistry now are experiencing considerable ferment and turmoil.

For instance, predental students now are being advised to pursue a rounded undergraduate curriculum. A number of schools, it may be recalled, have begun to provide instruction for dental students in the treatment of the chronically ill. Some schools are teaching students to use portable equipment. One might anticipate, within a few years, that the chronically ill, homebound patients and those in mursing homes will receive needed dental care from private dental practitioners. Here is a trend which must continue, if the younger population is to value dentistry as a service.

A number of schools have started to teach students to make use of multiple dental assistants. Later in today's program the efficient use of dental assistants will be discussed. Some of the time of these dental assistants undoubtedly will be used for educational purposes. A new interest exists in the development of departments of social or preventive dentistry within dental schools. In all instances, however, the success of such new departures will demand the assignment of prestige to equal that gained by the clinical practice of dentistry.

One should be forgiven for suggesting that the imperative priority for motivating patients to seek dental care on a preventive basis is to continue and to accentuate newer trends in the recruitment of students, who already possess an interest, and then to teach these students that social behavior has become important.

Essential Changes in the Practice of Dentistry. What changes seem necessary in the practice of dentistry? It may be helpful to note briefly the characterization of the private dental practitioner as he has been seen by his friendsnot his enemies. He has been the only health professional who encases himself in a five by eight room, works from nine till five, four and a half days a week, and never works nights; has no relation to the community around him; and his major mode of relaxation is building "hi-fi" sets, making recreation rooms in his basement, and plaving golf during one afternoon a week-typically with another dental practitioner. He has had no connection with a hospital or with a school, other than belonging to the P. T. A. where his children went to school.

More importantly, the older private dental practitioner became the way he was because that was the way he wanted to be, and because he wanted to enjoy the factors which attracted him to dentistry in the first place. As has been noted, in study after study of career-aspirations, dental students and predental students state that they want to go into dentistry so that they "can be their own boss and set their hours," "make a lot of money," "do things with their hands," and "be in a prestigeful profession."

This characterization, note, has begun to change. For instance, dentists are attending today's meeting which has as its focus, instead of dental technics, dental health education. Many have travelled long distances to get here. Personal association with a number of dentists and their wives has indicated-after a successful campaign for fluoridation-that they have decided that community activities were worthwhile, indeed. A large number of dentists throughout this country recently have participated in the programs of headstart. These activities, too, merely are germinal, and they must be accentuated greatly before one should expect the public to change. Perhaps current indications that students have an 
awakening interest in group-practice, in utilizing assistants, and even in joining group-practices which include physicians may have important impacts.

The Effects of Dental Health Education. Now, having reported a group of studies, for which this reporter had no responsibility, and having pointed to some changing practices of the profession, which need acceleration, a discussion of the relevance of the data presented at the beginning should be in order. What is the potential gain from dental health education and where should it be accomplished?

At least two answers to this question are available. The first is that people learn frequently when the subject being taught has maximal utility. The patient, who comes to the dental office in pain, may be in the ideal position to learn the steps that can be taken to avoid future pain. A group of studies carried out in the laboratories of social psychology indicate, furthermore, that people change relevant attitudes when they receive communications from credible sourcesthose defined as trustworthy and expert-more than they do from sources which they define as less trustworthy. ${ }^{15}$ It is likely that the dentist in his office is defined as entirely credible.

It would seem appropriate for the dentist, his hygienist and his assistant to spend some part of each dental appointment to point out to the patient the results of his failure to follow a preventive regime. The dentist might use this opportunity to point out that the patient is indeed susceptible to dental problems, otherwise he would not be in the office, that if these problems are not treated promptly, more serious problems can and will occur, and if the patient could come to the office on the basis of periodic maintenance, the dentist would be able to preserve the patient's teeth during a lifetime. Cards, for a system of recalling, furnish an ideal mechanism for convincing the patient that the dentist is concerned about the maintenance of a preventive regime. It should be noted, however, that only a minority of patients visit dentists' offices during any year. Dental health education in the dentist's office is likely to reach a much smaller part of the population than some of the other procedures available.

The second answer to "Where should dental health education be provided?" is that it seems sensible to embody ideas within a general educational environment. Children are in school for approximately six hours a day for over 200 days a year. More and more schools and school administrations appear anxious to have children learn about health matters; such administrations seem unlikely to have the technical competence to develop programs in dental health education. It is at this level that the health professional and the private dental practitioner need to take the lead in the development of a curriculum for teaching correct dental habits.

Some words of caution arise at this point. First, dental health education can be but a small portion of the educational stimuli which affect the child and easily can be lost. Secondly, materials for teaching dental health appear to emphasize memorization of facts, such as the parts of the tooth and the dates of eruption of teeth. Little functional utility can be found in such knowledge. Thirdly, as was indicated much earlier, the rates of repair for teeth seem to be similar within families. ${ }^{6}$ It may be impractical to expect that a child can influence his mother, who probably serves as the decision-maker on health practices in the family, to the point that she will carry out a preventive regime both for him and for herself.

Of relevance to the development of materials for teaching dental health, are the findings from two studies completed and reported recently. It was found, contrary to some findings reported about 10 years ago, that communications intended to produce high fear about dental problems did not produce less change 
in the attitudes and the behavior of school children universally than did communications intended to produce low fear about dental problems. Instead, the newer findings indicated that children in junior high school, from the lowerincome families changed more as a result of communications that induced high fear, while children from middle-class families changed more as a result of more moderate communications. ${ }^{16,1 ;}$ These data accentuate the need to pattern one's approach to one's audience and not to expect that a single, universal message will produce the effects desired.

Granted that a low degree of knowledge exists about the method which is likely to have an effect, either in the dental office or in the school, a major need demands evaluatory and experimental studies of community dental health in which different means of communicating ideas are tried and different kinds of material are provided in order to determine the technics which have the greatest effectiveness in persuading a population to gain preventive dental care for itself.

As a final statement, it appears pertinent to point out that the practice of dentistry grows exciting as it moves from the status of a guild to that of a profession. The key to its new world now must be innovation rather than status quo.

\section{Bibliography}

1. Kegeles, S. S. Why people seek dental care; a review of present knowledge. Am. J. Pub. Health, 51:1306-11, Sept. 1961.

2. Haefner, D. P., et al. Preventive actions concerning dental disease, tuberculosis and cancer. Accepted for publication in Pub. Health Rep. in 1967.

3. Kegeles, S. S. Some motives for seeking preventive dental care. Am. Dent. A. J., 67:90-8, Julv 1931 .

4. …. Why people seek dental care; a test of a conceptual formulation. J. Health and Human Behav., 4:166-73, Fall 1963.

5. Kriesberg, Louis, and Treiman, Beatrice. Socio-economic status and the utilization of dentist's services. Am. Col. Dent., 27:147-65, Sept. 1960.

6. Tyroler, H. A., Johnson, A. L., and Fulton, J. T. Patterns of preventive health behavior in populations. J. Health and Human Behavior, 6:128-40, Fall 1965.

7. Rosenstock, I. M. Why people use health services. Milbank Mem. Fund Quar, Part II, 44:94-127, July 1966 .

8. Kirscht, J. P., et al. A national study of health beliefs. J. Health and Human Behavior, 7:248-54, Winter 1966.

9. University of Chicago, National Opinion Research Center. Factors associated with preventive dental practice. Report No. 69, (Chicago), National Opinion Research Center, 1959. IV $+161 \mathrm{P}$. mimeog.

10. Crain, R. L., and Rosenthal, D. B. The fluoridation decision: community structure and innovation; final report. Philadelphia, National Analysts, Inc., 1964. XV $+305 p$. (p.100-1)

11. Vermillion, J. R., Gailbreath, M. N., and Rollins, P. L. Dental care for the chronically ill and aged; a community experiment. P. H. S. Publication. No. 899, Washington, Government Printing Office, $1961 . \mathrm{V}+54 \mathrm{p}$.

12. Lefcowitz, M. J., and Ireland, Loli. Interest in dentistry; a pilot study of high school students. I. Effect of social status and academic ability. I. Dent. Educ., 27:43-54, Mar. 1963.

13. More, D. M., and Kohn, Nathan, Jr. Some motives for entering dentistry. Am. J. Sociol., $66: 48-53$, July 1960.

14. Quarantelli, F. L. Attitudes of students toward specialization and research. Am. Col. Dent. J., $27: 100-7$, June 1960 .

15. Aronson, Elliott, Turner, Judith, and Carlsmith, J. M. Communicator credibility and communication discrepancy as determinants of opinion change. J. Abnorm. and Soc. Psychol, $67: 31-6$, July 1963 .

16. Haefner, D. P. Arousing fear in dental health education. J. Pub. Health Dent., 25:140-6, $F_{a}$ ll 1965.

17. Leventhal, Howard, Singer, Robert, and Jones, Susan. Effects of fear and specificity of recommendation upon attitudes and behavior. J. Personality and Soc. Psychol., 2:20-9, July 1965. 